Revista Triângulo

ISSN 2175-1609

\title{
OBJETOS EDUCACIONAIS VIRTUAIS NO ENSINO DE FÍSICA: ANÁLISE DE UMA COLEÇÃO DE LIVROS DIDÁTICOS
}

\author{
VIRTUAL EDUCATIONAL OBJECTS IN PHYSICS TEACHING: ANALYSIS OF A TEXTBOOKS \\ COLLECTION
}
OBJETOS EDUCACIONALES VIRTUALES EN LA ENSEÑANZA DE LA FÍSICA: ANÁLISIS DE UNA COLECCIÓN DE LIBROS DIDÁCTICOS

\author{
Thaianne Lopes de Souza \\ E-mail: thaiannefisica@gmail.com \\ Sandro Rogério Vargas Ustra \\ E-mail: srvustra@,ufu.br \\ Universidade Federal de Uberlândia - UFU
}

\begin{abstract}
RESUMO
O presente artigo contempla resultados de uma análise de livros didáticos de Física quanto à apresentação de objetos educacionais virtuais e sua articulação a contextos escolares típicos do Ensino Médio. Objetiva-se compreender as principais características destes objetos, além de analisar sua qualidade pedagógica, visto que usualmente, apesar de propostos, não comparecem nas práticas de sala de aula. Neste recorte apresentam-se os resultados obtidos na análise de três volumes de uma coleção utilizada em escolas públicas e aprovadas no âmbito do Programa Nacional do Livro Didático. Adotou-se uma abordagem qualitativa inspirada na análise de conteúdo. A partir dos resultados obtidos foi possível concluir que os objetos educacionais virtuais são propostos em quantidade expressiva, mas ainda não apresentam atributos que os destaquem como um recurso mais vantajoso em relação ao texto impresso nas condições usualmente encontradas nas salas de aula.
\end{abstract}

PALAVRAS-CHAVE: Livro didático. Objetos educacionais virtuais. Ensino de Física.

\section{ABSTRACT}

The present article contemplates results of an analysis of Physics textbooks regarding the presentation of virtual educational objects and its articulation to typical school contexts of High School. The objective is to understand the main characteristics of these objects, besides analyzing their pedagogical quality, because usually, although proposed, they do not show up in classroom practices. In this section we present the results obtained in the analysis of three volumes of one collection used in public schools and approved under the National Textbook Program. A qualitative approach was adopted based on content analysis. From the results obtained it was possible to conclude that virtual educational objects are proposed in significant quantity, but still do not present attributes that highlight them as a more advantageous resource in relation to the text printed in the conditions usually found in classrooms.

KEYWORDS: Textbook. Virtual educational objects. Physics teaching.

\section{RESUMEN}

El presente artículo contempla resultados de un análisis de libros didácticos de Física en cuanto a la presentación de objetos educativos virtuales y su articulación a contextos escolares típicos de la Enseñanza 
Revista Triângulo

ISSN 2175-1609

Media. Se pretende comprender las principales características de estos objetos, además de analizar su calidad pedagógica, ya que muchas veces, a pesar de propuestos, no se presentan en las prácticas de aula. En este recorte se presentan los resultados obtenidos en el análisis de tres volúmenes de una colección utilizada en escuelas públicas y aprobada en el ámbito del Programa Nacional del Libro Didáctico. Se adoptó un enfoque cualitativo a través del análisis de contenido. A partir de los resultados obtenidos fue posible concluir que los objetos educativos virtuales son propuestos en cantidad significativa, pero aún no presentan atributos que los destaquen como un recurso más ventajoso en relación al texto impreso en las condiciones usualmente encontradas en las aulas.

PALABRAS-CLAVE: Libro didáctico. Objetos educativos virtuales. Enseñanza de la Física.

\section{INTRODUÇÃO}

As inovações no ensino de Ciências destacaram-se principalmente a partir da década de 1950 com o desenvolvimento de vários projetos norte-americanos sediados em importantes universidades e institutos de pesquisa, dos quais alguns se estenderam ao Brasil, com foco na experimentação e utilização de materiais didáticos específicos. Com a estruturação da área de pesquisa em Educação em Ciências, ampliou-se a necessidade de novos estudos e reflexões para a melhoria da aprendizagem, surgindo várias vertentes como concepções alternativas, história e filosofia da ciência, uso dos modelos mentais, resolução de problemas, dentre outros. Atualmente, com advento tecnológico e da internet, os objetos educacionais virtuais (OEV) têm se constituído em foco de investigação de muitos grupos de pesquisa.

No ensino de Física, os recursos tecnológicos podem contribuir para a compreensão de vários conceitos e fenômenos por vezes bastante abstratos, auxiliando nas distintas modalidades de educação (formal, não formal e informal). Além disso, têm uma aplicação muito diversificada, sendo utilizados para medições, representações gráficas, avaliações, apresentações, modelagens, animações e simulações.

Pensando na qualidade e nos conteúdos que carregam os $\mathrm{OEV}$, torna-se relevante analisar os que integram os livros didáticos de Física utilizados nas escolas públicas, os quais são aprovados no âmbito do Programa Nacional do Livro Didático (PNLD).

O PNLD tem como principal objetivo subsidiar o trabalho pedagógico dos professores por meio da distribuição de coleções de livros didáticos aos alunos da Educação Básica. Essas coleções são produzidas por várias editoras e passam por avaliações realizadas por 
Revista Triângulo

ISSN 2175-1609

professores (da Educação Básica e universidades) credenciados ao PNLD, de acordo com os objetivos e critérios propostos pelos editais que orientam seu desenvolvimento.

Segundo o edital do PNLD de 2015 (BRASIL, 2013), os editores poderiam apresentar para a avaliação livros impressos e digitais, sendo que estes últimos necessariamente precisariam conter ícones para acesso aos OEV. As coleções que incluem os formatos impresso e digital são denominadas Tipo 1 e aquelas que apresentam apenas o formato impresso de Tipo 2.

Quanto aos livros impressos de coleções Tipo 1, estes devem apresentar uma identificação para os OEV e permitir uma efetivação autônoma e suficiente da proposta didático-pedagógica da obra, independente dos livros digitais.

Os livros digitais deveriam conter o mesmo conteúdo dos livros impressos integrados a OEV, isto é, incluir vídeos, imagens, áudios, textos, gráficos, tabelas, tutoriais, aplicações, mapas, jogos educacionais, animações, infográficos, páginas web e outros elementos. Além disso, precisariam disponibilizar um índice de referência dos OEV. Dessa forma, os objetos poderiam ser acessados tanto pelo índice de referência como pelos ícones nas páginas em que estejam inseridos.

Por outro lado, as coleções Tipo 2, tipicamente mais utilizadas pelos professores e alunos nas escolas, prescindem dessa apresentação mais explícita dos OEV; mas, dadas as características do Edital do PNLD, o texto impresso acaba sendo comum ao livro digital. Portanto, os OEV também estão presentes nestas coleções através das indicações de suas fontes na internet.

Desta forma, temos como objetivo inicial caracterizar os OEV indicados nos livros didáticos impressos de Física (Tipo 2) propostos no PNLD 2015, descrevendo-os, identificando suas finalidades e propondo categorias de análise para em seguida fazer inferências sobre a relevância e qualidade desses objetos para o processo de ensinoaprendizagem. Em etapa posterior, os resultados obtidos nesta etapa serão comparados criticamente com as análises desenvolvidas para coleções do PNLD 2018. 
Revista Triângulo

ISSN 2175-1609

\section{REFERENCIAL TEÓRICO}

Existem algumas definições para os objetos educacionais virtuais que se entrelaçam. Para Wiley (2000), os objetos educacionais virtuais podem ser qualquer fonte digital que poderá ser reutilizada para a aprendizagem. Para Leão e Souto (2015), trata-se de recursos digitais dinâmicos, interativos e reutilizáveis em diferentes ambientes de aprendizagem elaborados a partir de uma base tecnológica e que foram desenvolvidos com fins educacionais, possibilitando tanto o uso de imagens, fotos, quanto trechos de vídeos, animações, página na web, simulações, entre outros. Já para Arantes e colaboradores (2010), são objetos digitais disponíveis na web, projetados especificamente com objetivos educacionais.

Os OEV se mostram como uma ferramenta pedagógica que utiliza um material didático envolvendo conteúdos específicos, interdisciplinaridade e recursos das tecnologias da informação e comunicação, que possibilitam repensar a educação considerando os espaços virtuais como espaços alternativos de aprendizagem, extrapolando o espaço confinado da sala de aula e a restrição apenas ao texto impresso do livro didático.

Os OEV carregam algumas características (LONGMIRE, 2000; BETTIO, 2003) como:

- a flexibilidade - construídos com início, meio e fim, os objetos são flexíveis, podendo ser reutilizados sem nenhum tipo de manutenção;

- a facilidade para atualização;

- customização - dada sua independência, os objetos podem ser utilizados diversas áreas e para diferentes objetivos;

- interoperabilidade - associada à reutilização dos objetos em plataformas e ambientes variados;

- aumento de valor de um conhecimento - considerando a possibilidade de sua reutilização, o objeto pode ser melhorado, levando à sua consolidação;

- indexação e procura - a padronização dos objetos permite facilitar sua busca em diferentes bases/bancos. 
Dessa forma, com tantas características positivas, os professores podem se valer das potencialidades destes recursos refletindo sobre informações, conteúdos e recursos pedagógicos, construindo relações significativas para os estudantes. Mas, torna-se necessário que tenham uma postura dinâmica, reflexiva e crítica sobre sua atuação, atendendo às contínuas demandas da profissão.

Neste sentido, Leão e Souto (2015) reafirmam a importância de uma formação que incentive a utilização das novas tecnologias para uma prática voltada a favorecer processos de aprendizagem, possibilitando aos estudantes atividades didáticas em que os recursos da informática sejam utilizados de forma criteriosa.

No entanto, muitos docentes ainda não atuam neste contexto por falta de tempo, por convicções contrárias ou mesmo por falta de acesso a esses recursos; ainda, há uma quantidade expressiva de não nativos da cultura digital, isto é, aqueles que não nasceram neste período e necessitam algum esforço para se inserirem nesta cultura digital, convivendo em meio a tantas transformações tecnológicas.

\section{MATERIAIS E MÉTODOS}

Para analisar os objetos educacionais virtuais que acompanham os livros didáticos de Física Tipo 2 do PNLD 2015, adotamos uma perspectiva qualitativa para a pesquisa, utilizando estratégias inspiradas na análise de conteúdo.

Surgida como método para analisar material jornalístico, a análise de conteúdo constituiuse como uma metodologia de pesquisa usada para descrever e interpretar o conteúdo de toda classe de documentos e textos, conduzindo a descrições qualitativas e quantitativas, que buscam ir além de uma simples leitura de texto; logo, através desta metodologia, é possível atingir uma compreensão dos significados latentes num processo de comunicação (CAREGNATO, 2006).

Para as pesquisas quantitativas, a análise de conteúdo busca a frequência de signos (palavras) ou características que se repetem ao longo do conteúdo do texto. No entanto, para as pesquisa qualitativas, essa metodologia procura pela presença ou ausência de uma dada 
característica que dê sentido aos signos, que permita compreender o contexto, que será reconstruído pelo pesquisador (CAREGNATO, 2006).

Neste sentido, a análise de conteúdo é definida como um conjunto de técnicas de análises das comunicações que utiliza procedimentos sistemáticos e objetivos de descrição do conteúdo das mensagens (BARDIN, 2011). E pode ser classificada em dois tipos: análise categorial e dedução frequencial.

$\mathrm{Na}$ análise categorial faz-se uma busca de temas que podem ser categorizados, desse modo uma série de signos são detectados e classificados por suas significações, isto é, buscam-se elementos em comum que são categorizados de acordo com os temas que forem surgindo. Essa é a técnica mais utilizada na análise de conteúdo.

Para o desenvolvimento dessa metodologia de pesquisa são consideradas três etapas: préanálise, exploração do material/tratamento dos resultados e interpretação. Inicialmente consiste em tratar as informações iniciando com uma pré-análise, momento de organização da pesquisa, na qual se escolhem os documentos, formulam-se hipóteses e se detalham os objetivos para a pesquisa; para isso faz-se necessária uma leitura flutuante para a fundamentação da interpretação. $\mathrm{Na}$ exploração do material são construídos os códigos, a partir dos dados, necessitando da aplicação de técnicas específicas de acordo com os objetivos da pesquisa. Deste modo os conteúdos serão transformados em unidades de análise. Por fim, no tratamento dos resultados e intepretações, as unidades serão categorizadas por semelhanças e diferenças e, a partir das categorias, serão constuídas as inferências e as interpretações (FRANCO, 2005).

Numa primeira abordagem, a partir do contato que mantemos com uma escola pública de Uberaba/MG, identificou-se a coleção do componente curricular de Física que é utilizada pelos professores e alunos. Trata-se da coleção Física: Ciência e Tecnologia, dos autores Carlos Magno A. Torres, Nicolau Gilberto Ferraro, Paulo Antonio de Toledo Soares e Paulo Cesar Martins Penteado, da Editora Moderna, 2014.

Com os três volumes (livros do aluno) que compõem a Coleção (aprovada no edital PNLD 2015), estabelecemos uma pré-análise identificando os OEV presentes, passando a caracterizar, de modo geral, a apresentação dos conteúdos e a qualidade do material. 
Revista Triângulo

ISSN 2175-1609

Todos os volumes da Coleção são compostos por oito capítulos cada um e, para apresentar sua organização, há uma parte indicada nas páginas iniciais como "Compreenda a estrutura da obra", a qual detalha essa composição. Há uma seção específica, principal objeto de análise dessa pesquisa, denominado "Navegue na web", a qual está disposta ao final de cada capítulo, com o objetivo de fornecer links para leituras complementares, indicação de aplicativos de simulações, links para experiências, vídeos, fotos e sugestões de animações.

Com relação aos links para experiências, notamos que as sugestões são válidas tanto para que o professor realize em sala como para que os alunos possam desenvolver em suas casas sem auxílio do professor.

Ao sugerir vídeos, as fontes indicadas são do Youtube, sendo que se dividem em explicações teóricas e demonstrações experimentais, isto é, há um link de vídeo em que professores de canais no Youtube explicam a parte conceitual e um link em que ensinam a desenvolver determinada experiência.

\section{ANÁLISE DOS DADOS E RESULTADOS}

Os OEV da coleção analisada são sugeridos em cada capítulo e estão descritos nas Tabelas 1,2 e 3 .

Tabela 1: Descrição dos OEV sugeridos em cada capítulo/Volume 1

\begin{tabular}{c|l}
\hline \multicolumn{1}{c|}{ Capítulo } & \multicolumn{1}{c}{ Objetos virtuais educacionais } \\
\hline Capítulo 1 & $\begin{array}{l}\text { Sugestão de 2 links de sites para leitura complementar ("Ciência: O que é } \\
\text { isso?" e "Matéria e suas propriedades"). }\end{array}$ \\
\hline Capítulo 2 & $\begin{array}{l}\text { Sugestão de 2 links de sites para leitura complementar ("Como tudo } \\
\text { funciona?" e "O relógio atômico brasileiro"). }\end{array}$ \\
\hline Capítulo 3 & $\begin{array}{l}\text { Sugestão de 2 links de aplicativos para simulação ("Adição de vetores", } \\
\text { aplicativo que permite efetuar graficamente a adição de até 5 vetores; e } \\
\text { "Sistema massa-mola", para simular um experiência com massas e molas } \\
\text { para ilustrar a lei de Hooke) e 1 link para leitura complementar (sobre o } \\
\text { funcionamento do freio ABS). }\end{array}$ \\
\hline
\end{tabular}




\section{$\Delta$ \\ Revista Triângulo \\ ISSN 2175-1609}

\begin{tabular}{|c|c|}
\hline Capítulo 4 & $\begin{array}{l}\text { Sugestão de } 3 \text { links para simulações ("Força e empuxo nos líquidos", } \\
\text { simulação de um experimento para determinar o empuxo de um líquido sobre } \\
\text { um corpo; "Pressão hidrostática em líquidos", simulação de um experimento } \\
\text { para determinar a pressão hidrostática em diferentes líquidos; e "Fluido não } \\
\text { newtoniano", sobre como fazer uma massa maluca e analisar o seu } \\
\text { comportamento), } 1 \text { link para experiência ("Dinâmica de fluidos", simulação } \\
\text { de escoamento de um fluido com a possibilidade de alterar parâmetros e } \\
\text { verificar os resultados previstos pela equação de Bernoulli) e } 1 \text { link para } \\
\text { leitura complementar ("Os projetos de Santos-Dumont", artigo com fotos). }\end{array}$ \\
\hline Capítulo 5 & $\begin{array}{l}\text { Sugestão de } 3 \text { links para simulações ("Galileo", aplicativo para análise de } \\
\text { diversos tipos de choques entre duas esferas; "Dia a dia educação", animação } \\
\text { sobre um modo prático para aumentar o torque, permitindo soltar o parafuso } \\
\text { de uma roda; "Simulador", simulação sobre torque) e } 2 \text { links de vídeos } \\
\text { (Desafio do centro de gravidade", vídeo sobre o equilíbrio de } 10 \text { pregos na } \\
\text { ponta de um; "Conservação do momento angular", explicação de um } \\
\text { professor sobre o momento angular). }\end{array}$ \\
\hline Capítulo 6 & $\begin{array}{l}\text { Sugestão de } 5 \text { links de simulações (applets da Física com simulações sobre } \\
\text { análise de energia potencial, cinética e mecânica). }\end{array}$ \\
\hline Capítulo 7 & $\begin{array}{l}\text { Sugestão de uma página na web - Leitura complementar (Observatório } \\
\text { nacional; contém textos, cursos e ferramentas para a formação e divulgação } \\
\text { dessa área no Brasil). }\end{array}$ \\
\hline Capítulo 8 & $\begin{array}{l}\text { Sugestão de } 2 \text { simulações (Applets Zur Physik - Walter Fendt, Aplicativo } \\
\text { sobre princípio da alavanca; Programa Educação Tutorial/UFPR, aplicativo } \\
\text { de polias) e } 2 \text { links para leituras complementares ("Como tudo funciona", } \\
\text { artigo sobre transmissão manual; “ } \pi \text { on - Ligado na Física!", nesse endereço } \\
\text { eletrônico é possível rever vários conceitos). }\end{array}$ \\
\hline
\end{tabular}

Fonte: Autoria própria.

Tabela 2: Descrição dos OEV sugeridos em cada capítulo/Volume 2

\begin{tabular}{c|l}
\hline Capítulo & \multicolumn{1}{c}{ Objetos virtuais educacionais } \\
\hline Capítulo 1 & $\begin{array}{l}\text { Sugestão de 2 links para leituras complementares (“A termometria nos } \\
\text { séculos XIX e XX", descreve aspectos importantes da evolução da medida de } \\
\text { temperatura; "Criogenia", detalha a técnica da criogenia). }\end{array}$ \\
\hline Capítulo 2 & $\begin{array}{l}\text { Sugestão de 2 leituras complementares ("Efeito Estufa", artigo elaborado } \\
\text { para aprofundar o tema; "O que posso fazer para evitar o aquecimento } \\
\text { global?", página para orientar a minimizar o aquecimento global) e 2 links } \\
\text { para simulação ("Comer \& Exercitar-se”, simulação de como a massa } \\
\text { corpórea varia com o tempo; "Efeito estufa", simulação que mostra como os } \\
\text { gases interferem o clima global). }\end{array}$ \\
\hline Capítulo 3 & $\begin{array}{l}\text { Sugestão de 2 aplicativos para simulação ("Comportamento das moléculas de } \\
\text { um gás", simulação para estabelecer diferentes parâmetros para as moléculas } \\
\text { de um gás; "Comportamento dos gases", simulação possibilita modificar as }\end{array}$ \\
\hline
\end{tabular}


Revista Triângulo

ISSN 2175-1609

\begin{tabular}{|c|c|}
\hline & variáveis de estado de um gás). \\
\hline Capítulo 4 & $\begin{array}{l}\text { Sugestão de } 2 \text { links para leitura complementar ("Como funcionam os } \\
\text { motores a vapor", artigo que explica o funcionamento desses tipos de } \\
\text { motores; "Como funcionam os motores de carros", artigo que explica o } \\
\text { funcionamento do motor de carro). }\end{array}$ \\
\hline Capítulo 5 & $\begin{array}{l}\text { Sugestão de } 2 \text { simulações ("Propagação de perturbações em uma corda", } \\
\text { simulação que é possivel visualizar os fenômenos ondulatórios; "Tanque de } \\
\text { ondas", aplicativo que permite manipular variáveis e visualizar fenômeno de } \\
\text { difração). }\end{array}$ \\
\hline Capítulo 6 & $\begin{array}{l}\text { Sugestão de } 2 \text { simulações ("Ondas sonoras", simulador em que é possível } \\
\text { ouvir sons de diferentes alturas e intensidades; "Fazendo ondas", simulação } \\
\text { permite que sons simples ou compostos de seus harmônicos sejam ouvidos). }\end{array}$ \\
\hline Capítulo 7 & $\begin{array}{l}\text { Sugestão de } 4 \text { links para simulações ("Cores", aplicativo para obter a luz } \\
\text { branca; "Eclipse lunar", aplicativo para visualização de eclipse; "Imagens de } \\
\text { objetos entre dois espelhos planos", aplicativo para alterar o ângulo entre } 2 \\
\text { espelhos; "Mistura de luzes e tintas", aplicativo sobre mistura das cores } \\
\text { primárias). }\end{array}$ \\
\hline Capítulo 8 & $\begin{array}{l}\text { Sugestão de } 1 \text { animação ("Óptica", animação sobre assuntos abordados na } \\
\text { óptica), } 1 \text { leitura complementar ("Telescópios", página da web sobre os tipos } \\
\text { de telescópios), } 2 \text { simulações ("A Física do arco-íris", aplicativo sobre } \\
\text { trajetória da luz através de uma gota; "Ajuda Mr. Magoo a observar o mundo } \\
\text { com outros olhos", simulação sobre defeitos de visão). }\end{array}$ \\
\hline
\end{tabular}

Fonte: Autoria própria.

Tabela 3: Descrição dos OEV sugeridos em cada capítulo/Volume 3

\begin{tabular}{c|l}
\hline Capítulo & \multicolumn{1}{c}{ Objetos virtuais educacionais } \\
\hline Capítulo 1 & $\begin{array}{l}\text { Sugestão de 2 simulações ("Eletrização por atrito", simulação disponível no } \\
\text { Phet; "Laboratório virtual de circuitos elétricos", simulação disponível no } \\
\text { Phet). }\end{array}$ \\
\hline \multirow{3}{*}{ Capítulo 2 } & $\begin{array}{l}\text { Sugestão de 2 vídeos ("Lei de Faraday e Lei de Lenz", vídeo para analisar os } \\
\text { fenômenos de indução eletromagnética e a Lei de Lenz; "Efeito Meissner", } \\
\text { vídeo disponível no youtube para constatar o efeito de Meissner) e 1 } \\
\text { simulação ("Laboratório de eletromagnetismo de Faraday", simulação para } \\
\text { análise da Lei de Faraday). }\end{array}$ \\
\hline Capítulo 3 & $\begin{array}{l}\text { Sugestão de 3 aplicativos para simulação ("Propagação de ondas } \\
\text { eletromagnéticas", aplicativo que mostra o comportamento dos campos } \\
\text { elétricos e magnéticos de uma onda eletromagnética; "Ondas de rádio e } \\
\text { campo eletromagnéticos", simulação para visualizar a geração de uma onda } \\
\text { eletromagnética; "Interferência de ondas", simulação que permite verificar a } \\
\text { interferência de vários tipos de ondas) e 1 link para leitura complementar } \\
\text { ("Como funciona o laser", leitura para compreender o funcionamento e } \\
\text { construção de um laser). }\end{array}$ \\
\hline
\end{tabular}


Revista Triângulo

ISSN 2175-1609

\begin{tabular}{|c|c|}
\hline Capítulo 4 & $\begin{array}{l}\text { Sugestão de } 9 \text { links para leitura complementar ("Balanço Energético"; } \\
\text { "Energia eólica"; "Biodiesel"; "Indústrias nucleares do Brasil"; "O acidente } \\
\text { de Goiânia"; "Associação Brasileira dos Fabricantes de latas de alta } \\
\text { reciclabilidade"; "Associação Técnica Brasileira das Indústrias automáticas } \\
\text { de vidro"; "Associação Brasileira de celulose e papel"; "Instituto Sócio- } \\
\text { ambiental dos Plásticos") }\end{array}$ \\
\hline Capítulo 5 & $\begin{array}{l}\text { Sugestão de } 1 \text { simulação ("Um exemplo de dilatação do tempo", simulação } \\
\text { que permite compreender a dilatação do tempo). }\end{array}$ \\
\hline Capítulo 6 & $\begin{array}{l}\text { Sugestão de } 3 \text { simulações ("Radiações eletromagnéticas", aplicativo que } \\
\text { permite visualizar a distribuição das intensidades das radiações } \\
\text { eletromagnéticas; "Modelos atômicos", aplicativo que simula a evolução dos } \\
\text { modelos atômicos; "Efeito fotoelétrico", aplicativo que simula o efeito } \\
\text { fotoelétrico e alterar o metal iluminado) e } 1 \text { leitura complementar ("Há mais } \\
\text { espaços lá embaixo", página completa com o discurso de Richard Feynman). }\end{array}$ \\
\hline Capítulo 7 & $\begin{array}{l}\text { Sugestão de } 2 \text { simulações ("Espalhamento Rutherford", aplicativo que } \\
\text { permite visualizar o espalhamento; "Fissão Nuclear", aplicativo que simula } \\
\text { uma fissão nuclear disparando nêutrons contra um núcleo de urânio) e } 2 \\
\text { leituras complementares ("Perigo nuclear no Japão", texto sobre como } \\
\text { funcionam os reatores nucleares; "Natureza morta", texto sobre a liberação de } \\
\text { radioatividade na natureza). }\end{array}$ \\
\hline Capítulo 8 & $\begin{array}{l}\text { Sugestão de } 5 \text { leituras complementares ("Funcionamento do telefone", artigo } \\
\text { explica sobre os princípios que permitem o funcionamento do telefone; } \\
\text { "Antonio Meucci", página na web que conta a história do inventor do } \\
\text { telefone; "Plasma: dos antigos gregos à televisão que você quer ver", artigo } \\
\text { que discute o conceito físico de plasma; "Cristais líquidos", artigo que analisa } \\
\text { as propriedades características dos cristais líquidos; "Cristais líquidos: um } \\
\text { sistema complexo de simples aplicação", artigo que apresenta o mundo dos } \\
\text { cristais líquidos). }\end{array}$ \\
\hline
\end{tabular}

Fonte: Autoria própria.

A partir das Tabelas 1, 2 e 3, temos uma descrição geral dos OEV, com a proposição total de 82 objetos, dentre simulações, leituras complementares, vídeos, experiências e animações. Estes estão distribuídos conforme indicado no Gráfico 1. 
Gráfico 1: Distribuição dos OEV presentes na Coleção

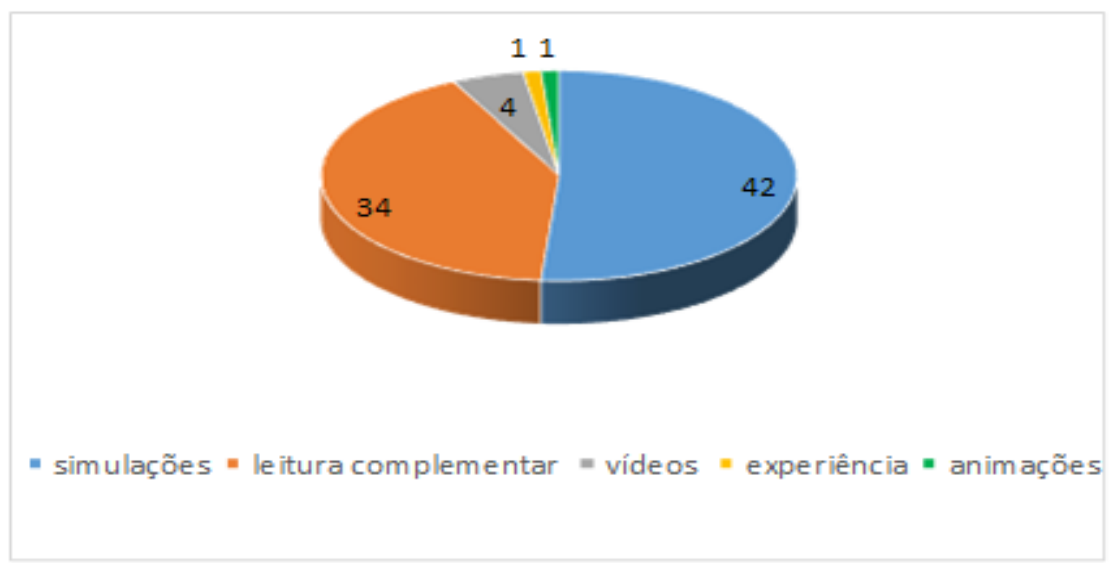

Fonte: Autoria própria.

Grande parte das sugestões consiste de simulações, das quais 21 foram desenvolvidas pelo Phet Colorado, página da web disponibilizada pela Universidade de Colorado com várias simulações nas áreas de ciências da natureza.

Já as leituras complementares sugeridas, de maneira geral, são artigos ou páginas na web de alguns programas educacionais ou científicos que disponibilizam textos informativos, bem como fotos sobre os conceitos, que possibilitam a busca pelo conhecimento por parte dos alunos, com uma quantidade bem expressiva de ilustrações.

Ao analisar cada objeto proposto, foi possível apontar uma unidade de contexto importante, qual seja, a sua finalidade na proposta pedagógica. Por exemplo, no Volume 1 em uma abordagem sobre as unidades de medidas e um pouco da história da física são sugeridos dois links de sites para complementação da leitura, com o objetivo de informar curiosidades sobre a Física. Neste mesmo volume são sugeridas também duas simulações para a aplicabilidade do conceito de força estudado ao longo do capítulo, caracterizando-se como um reforço ao conceito. Em outro capítulo, ao final do volume, é sugerido um endereço eletrônico em que o aluno pode complementar o estudo com conceitos que não foram abordados de forma mais detalhada, tratando-se de um objeto complementar ao conteúdo. 
Revista Triângulo

ISSN 2175-1609

Dessa forma, a partir da análise dos objetos presentes nos três volumes e considerando suas finalidades, pudemos categorizar os OEV segundo curiosidade, reforço e complemento. A categoria de curiosidade remete aos OEV que tratam de fatos desconhecidos ou assuntos relacionados ao que é abordado nos capítulos. A categoria reforço retrata os OEV que servem para fixar, extrapolar os conceitos abordados ao longo dos capítulos, enquanto a categoria complemento inclui os objetos voltados a acrescentar alguma informação ou atributo do que já havia sido tratado ao longo dos capítulos.

A partir do gráfico das categorias dos $\mathrm{OEV}$, podemos interpretar que os objetos propostos ao longo dos volumes são sugeridos muito mais para reforçar os conceitos abordados e visualizá-los, do que para complementá-los ou fornecer informações novas ou fatos desconhecidos.

O Gráfico 2 representa como os OEV estão categorizados ao longo dos volumes.

Gráfico 2: Finalidades dos OEV da Coleção

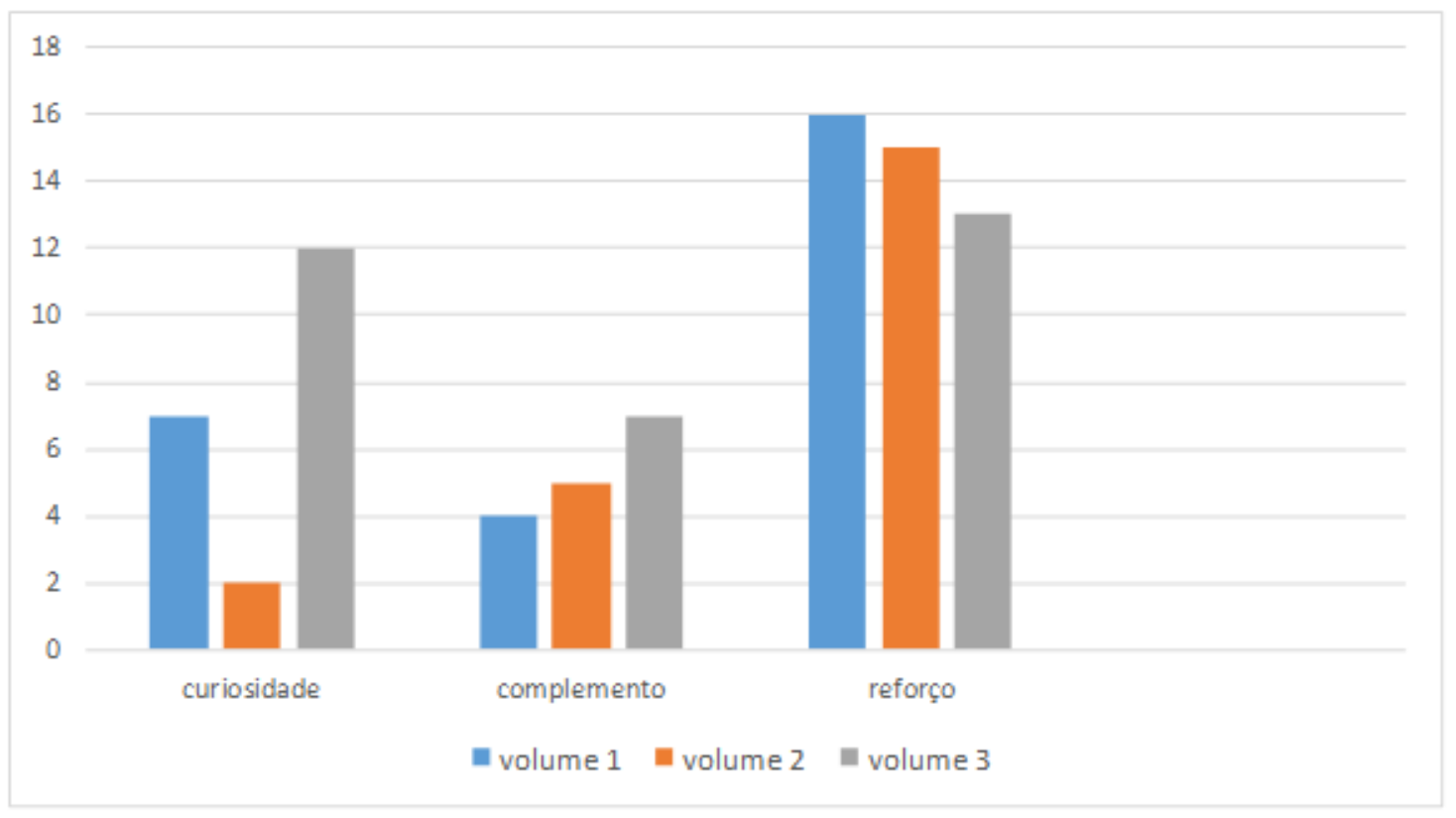

Fonte: Autoria própria.

Assim, os OEV são entendidos muito mais com a finalidade de um reforço ao conteúdo do que de uma curiosidade ou um complemento, apesar de serem sempre sugeridos ao final 
de cada capítulo, não se constituindo em uma parte fundamental do processo de ensinoaprendizagem. Isto pode representar um importante fator para explicar sua pouca utilização tanto pelos alunos quanto pelos professores.

\section{CONSIDERAÇÕES FINAIS}

Com base nos resultados obtidos foi possível concluir que a coleção analisada apresenta objetos educacionais virtuais diversificados, apesar de não se tratar do Tipo 1 (que inclui a versão digital). Trata-se de uma proposta bem avaliada no Guia do PNLD 2015 (BRASIL, 2014) que apresenta um número expressivo de objetos educacionais virtuais relacionados à parte conceitual, o que pode contribuir para a aprendizagem em Física.

A distribuição dos $\mathrm{OEV}$ ao longo da coleção indica uma priorização de conteúdos conceituais secundários, em termos de relevância na estrutura conceitual da Física. Assim, conceitos relacionados a princípios e leis fundamentais da mecânica, como as leis de Newton, lei da gravitação universal e princípio da conservação da energia, leis da termodinâmica, leis do eletromagnetismo, por exemplo, são carentes destes recursos.

Analisando o Gráfico 2 é possível inferir que a grande maioria dos OEV sugeridos ao longo da coleção, sempre ao final dos capítulos, devem ser utilizados como reforço para a aprendizagem dos conceitos abordados e acabam não apresentando de forma expressiva atributos que os destaquem como um recurso mais vantajoso em relação ao texto impresso em condições usualmente encontradas nas salas de aula. Nesse sentido, até por se tratarem de novas tecnologias, os professores poderão considerá-los inadequados para utilização no seu cotidiano de trabalho.

Nessa ênfase ao reforço, curiosidade ou complemento, conferida aos OEV, as atividades experimentais propostas deixam de contemplar um caráter investigativo e requerem uma atenção adicional por parte do professor. Esse aspecto é destacado no próprio Guia do PNLD, juntamente com a observação da necessidade de se fazer uma problematização com a história da ciência, já que na Coleção predominam aspectos resumidamente biográficos (BRASIL, 2014). 
Dessa maneira, torna-se importante que o professor faça uma articulação criteriosa das sugestões de OEV do livro didático ao seu planejamento didático, na perspectiva de aprimorar o processo de ensino-aprendizagem, além de utilizar efetivamente essa tecnologia em sala de aula.

Cabe ainda ressaltar que, apesar da coleção apresentar essas propostas dos OEV, considerando a natureza e as exigências para sua efetiva utilização em sala de aula, muitos alunos e professores continuam inertes a essa realidade tecnológica, devido a vários fatores, incluindo às dificuldades de utilização, falta de estrutura da escola, número reduzido de aulas, falta de tempo para a própria preparação do professor de aulas que incluem o uso de objetos virtuais educacionais, dentre outros.

Pensando na atuação docente, seria desejável que os livros didáticos trouxessem os OEV articulados de forma significativa na proposta pedagógica, com orientações tanto para professores quanto para alunos quanto as suas possíveis utilizações e abordagens, mesmos se tratando de coleções didáticas Tipo 2. Além disso, resta ainda como desafio ao professor dispor de meios e condições para que se possa aplicar e desenvolver atividades diferenciadas que propiciem um melhor processo de ensino-aprendizagem utilizando OEV. Certamente que o compartilhamento entre professores de propostas para o uso dos OEV e de relato de suas vivências profissionais contribuiria para um melhor aproveitamento de recursos tecnológicos em sala de aula, uma vez que já se fazem presentes em nosso cotidiano, mesmo que sejam apenas indicações de uso.

Dessa forma, é importante se poder contar com análises, levantamentos, subsídios práticos, experiências, enfim, contribuições efetivas que auxiliem os professores e alunos a implementarem o uso das tecnologias em sala de aula, especialmente a partir dos objetos educacionais virtuais.

\section{REFERÊNCIAS}

ARANTES, A. R. et. al. Objetos de aprendizagem no Ensino de Física. In: Física na Escola, v.11, n.1, 2010.

BARDIN, L. Análise de Conteúdo. São Paulo: Edições 70, 2011. 
Revista Triângulo ISSN 2175-1609

BETTIO, R. Avaliações Gráficas e Dinâmicas Aplicadas a Ambientes Virtuais de Aprendizagem. Dissertação de Mestrado, Programa de Pós-Graduação em Engenharia de Produção, UFSC, Florianópolis, 2003.

BRASIL. Guia de livros didáticos: PNLD 2015: Física: Ensino Médio. Brasília: Ministério da Educação, Secretaria de Educação Básica, 2014.

BRASIL. Secretária de Educação Básica. Edital de convocação para o processo de inscrição e avaliação de obras didáticas para o programa nacional do livro didático PNLD 2015. Brasília, 2013. Disponível em: <http://www.fnde.gov.br/programas/livrodidatico/livro-didatico-editais/item/4032-pnld-2015> Acesso em: 17 mai. 2017.

CAREGNATO, R. C. A.; MUTTI, R. Pesquisa Qualitativa: análise de discurso x análise de conteúdo. In: Texto \& Contexto - Enfermagem, Florianópolis, 15(4), p. 679-84, 2006.

FRANCO, Maria Laura P. B. Análise de conteúdo. Brasília: Líber Livro, 2005.

LEÃO, M. F.; SOUTO, D. L. P. Objetos educacionais digitais para o Ensino de Física. In: Revista Tecnologias na Educação, n. 13, p. 01-12, 2015.

LONGMIRE, W. A Primer on Learning Objects. American Society for Training \& Development. Virginia, 2000.2 Disponível em: $<$ http://www.learningcircuits.org/mar2000/primer.htm>.

MIRANDA, M. S. Objetos virtuais de aprendizagem aplicados ao ensino de física - uma sequência didática desenvolvida e implementada nos conteúdos programáticos de física ondulatória, em turmas regulares do nível médio de escolarização que utilizam um sistema apostilado. Dissertação de Mestrado em Ensino de Ciências, UFSCAR, São Carlos, 2014.

WILEY, D. A. The Instrucional use of Learning Objects. Versão online, 2000. Disponível em: <www.reusability.org/read/chapters/wiley.doc> Acesso em: 04 abr. 2018. 